\title{
Announcement: New Associate Editor
}

We are happy to welcome Georg H. Hoffstaetter of Cornell University as a new Associate Editor of Physical Review Special Topics - Accelerators and Beams. He will be assuming the position formerly held by the late Francesco Ruggiero.

Published 13 June 2007

Frank Zimmermann

Editor

DOI: 10.1103/PhysRevSTAB.10.060001

PACS numbers: 01.10.Cr 